\title{
Classical conditioning for preserving the effects of short melatonin treatment in children with delayed sleep: a pilot study
}

\section{Annette van Maanen' \\ Anne Marie Meijer' \\ Marcel G Smits ${ }^{2}$ \\ Frans J Oort'}

'Research Institute Child Development and Education, University of Amsterdam, Amsterdam, ${ }^{2}$ Centre for Sleep-Wake Disorders and Chronobiology, Hospital Gelderse Vallei, Ede, the Netherlands
Correspondence: Annette van Maanen Research Institute Child Development and Education, University of Amsterdam, PO Box 15776, I00I NG Amsterdam, the Netherlands

Tel +3। 205251235

Fax +3। $20525 \mid 500$

Email a.vanmaanen@uva.nl
This article was published in the following Dove Press journal:

Nature and Science of Sleep

9 March 2017

Number of times this article has been viewed
Abstract: Melatonin treatment is effective in treating sleep onset problems in children with delayed melatonin onset, but effects usually disappear when treatment is discontinued. In this pilot study, we investigated whether classical conditioning might help in preserving treatment effects of melatonin in children with sleep onset problems, with and without comorbid attention deficit hyperactivity disorder (ADHD) or autism. After a baseline week, 16 children (mean age: 9.92 years, 31\% ADHD/autism) received melatonin treatment for 3 weeks and then gradually discontinued the treatment. Classical conditioning was applied by having children drink organic lemonade while taking melatonin and by using a dim red light lamp that was turned on when children went to bed. Results were compared with a group of 41 children (mean age: 9.43 years, 34\% ADHD/autism) who received melatonin without classical conditioning. Melatonin treatment was effective in advancing dim light melatonin onset and reducing sleep onset problems, and positive effects were found on health and behavior problems. After stopping melatonin, sleep returned to baseline levels. We found that for children without comorbidity in the experimental group, sleep latency and sleep start delayed less in the stop week, which suggests an effect of classical conditioning. However, classical conditioning seems counterproductive in children with ADHD or autism. Further research is needed to establish these results and to examine other ways to preserve melatonin treatment effects, for example, by applying morning light.

Keywords: melatonin, classical conditioning, children, delayed sleep

\section{Introduction}

Sleep problems are common among children, with reported prevalence rates as high as $30 \%-40 \%{ }^{1,2}$ Considering these high prevalence rates and the negative consequences of sleep problems on mood, behavior, and school performance, 3,4 it is important to treat these problems. Moreover, sleep problems in childhood predict later behavioral and emotional problems, ${ }^{5,6}$ which stresses the importance of early intervention.

Sleep problems can have different manifestations and causes requiring different types of treatment. In the present study, we focused on children with chronic sleep onset problems related to a delayed melatonin onset. Melatonin is a hormone produced by the pineal gland in the brain and is a marker of the circadian rhythm. Circadian rhythms, among which is the circadian rhythm of sleep, are orchestrated by the suprachiasmatic nucleus, located in the hypothalamus. ${ }^{7}$ It regulates the circadian rhythm of melatonin secretion and the circadian rhythm of sleepiness and alertness. Melatonin secretion starts to rise in the evening. ${ }^{8}$ In some children, melatonin secretion is delayed, which is associated with falling asleep late and difficulty awakening in the morning. Exogenous 
melatonin, if well timed and given in the appropriate dose, may advance the circadian rhythm and thereby advance sleep onset and offset. ${ }^{9}$

Several studies indeed found positive effects of melatonin treatment on sleep onset problems in children ${ }^{10-12}$ and also on health, ${ }^{11}$ behavior problems, and parenting stress. ${ }^{13}$ This was also found for children with attention deficit hyperactivity disorder (ADHD) and autism, ${ }^{14,15}$ disorders with a high comorbidity with sleep problems. ${ }^{16-19}$ However, removing melatonin will make the circadian rhythm revert to baseline levels if no other "zeitgeber", such as bright morning light, ${ }^{20}$ is added. Indeed, previous research showed that the positive effects of melatonin disappeared after discontinuing short-term treatment, ${ }^{13}$ indicating that treatment should be continued for a longer period of time. Yet, unnecessary long-term treatment is not desirable considering that there is a (theoretical) risk of delayed puberty onset associated with long-term melatonin use, although several longitudinal studies did not find any deviations when comparing children who used melatonin for a long time compared to the general population. ${ }^{21-23}$

The question then arises how the positive effects of melatonin treatment can be preserved when treatment is discontinued after a short period. A suggestion comes from research on classical conditioning. Classical conditioning is a learning principle originally described by Pavlov. ${ }^{24} \mathrm{He}$ showed that, after coupling a neutral stimulus (eg, a tone) to a stimulus that naturally evokes a specific response (stimulus: food, response: salivation), the former neutral stimulus can in itself evoke that response (tone evokes salivation). In the classical conditioning theory, the stimulus that automatically evokes a certain response is called an unconditioned stimulus (US). The response that is evoked by the US is called the unconditioned response (UR). The former neutral stimulus that leads to the same response after the learning process is called the conditioned stimulus (CS). The response that is now evoked by the CS is called the conditioned response (CR).
This principle has been applied to patients with insomnia. ${ }^{25,26}$ Evans and Bond treated a 45-year-old man with insomnia with methohexital sodium (US) while asking him to count (CS). The methohexital sodium made the man fall asleep (UR), and after some trials without using methohexital sodium but still counting (CS), the man reported that his sleep had improved, suggesting that the counting had become a CS resulting in better sleep (CR). A similar result was found by Poser et al, ${ }^{26}$ who treated a man with insomnia with methohexitone injections (US) while listening to the ticking of a metronome (CS). After a number of trials, the man reported clinical improvement when he kept using the metronome. In addition to the studies described previously, a recent study $^{27}$ discussed the literature on classical conditioning in relation to placebo response. It was found that conditioning, as a "learned placebo response", can influence peripheral immune functions as well as disease symptoms and disease progress. In the aforementioned studies, forward conditioning was used, ie, the onset of the CS precedes the onset of the US to signal that the US will follow. Generally, the UR starts immediately or shortly after the US.

The results described previously suggest that classical conditioning might be successful in preserving the effects of short-term melatonin treatment. To investigate this novel idea, we conducted a pilot study with a sample of children with chronic sleep onset insomnia, associated with a delayed melatonin onset. Their sleep behavior was assessed on 41 consecutive days: before melatonin treatment (1 week), during treatment and conditioning (3 weeks), during half-dose treatment (1 week), and after stopping treatment (1 week) (Figure 1). After baseline, classical conditioning was applied. As it takes some time to become sleepy after melatonin intake, we used two conditioning procedures. Children drank organic lemonade while taking melatonin, and a dim red light lamp was turned on when children went to bed. The daily assessments were compared to the daily assessments of

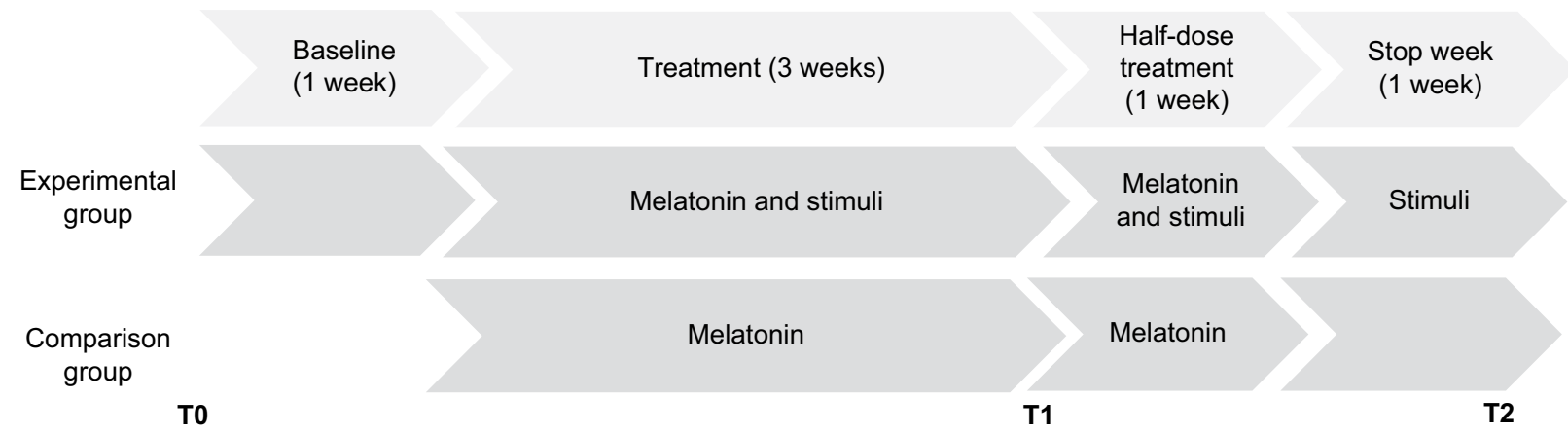

Figure I Study design.

Notes: T0 represents baseline; TI represents end of treatment; T2 represents end of stop week. 
children in a previous study who underwent the same procedure but without the conditioning of melatonin treatment. ${ }^{13}$ In both groups, a substantial proportion of children also had ADHD or autism (31\% in the experimental group and 34\% in the comparison group). In this way, we aimed to test the hypothesis that classical conditioning could help to preserve the effects of short-term melatonin treatment in children with chronic sleep onset insomnia related to a delayed melatonin onset, and we tested whether the effects were different for children with and without ADHD or autism.

\section{Methods}

\section{Participants}

The study was conducted in the Centre for Sleep-Wake Disorders and Chronobiology in the hospital. Children were referred to the hospital by their general practitioners because of their chronic sleep onset problems. Inclusion criteria for participation were 1) age between 5 and 12 years; (2) the child has chronic sleep onset problems defined as a) complaints of sleep onset problems expressed by parents and/or child, b) occurrence on at least 4 days/week for longer than 1 year, c) average sleep onset later than $20: 15 \mathrm{~h}$ for children at age 5 years and for older children 15 min later per year, and d) average sleep latency exceeding $30 \mathrm{~min}$; 3 ) the child attends a regular school (IQ is in the normal range); and 4) parents of the child have sufficient command of the Dutch language to understand the treatment and to complete the questionnaires. Children were not eligible for participation if 1) the child had a diagnosis of another sleep disorder (eg, restless legs syndrome, narcolepsy, and obstructive sleep apnea syndrome) and/or 2) the sleep onset problems were caused by physical problems (eg, pain). Table 1 gives a description of the experimental and comparison groups.

\section{Procedure}

The study was approved by the ethical committee of the Research Institute of Child Development and Education of the University of Amsterdam. Parents gave active informed consent for participation. Before their first appointment in the hospital, dim light melatonin onset (DLMO), the clock time at which the endogenous melatonin secretion reaches a certain threshold, was measured in saliva. Parents were asked to instruct their children to chew on cotton plugs according to a predetermined schedule for one evening. ${ }^{11,15}$

In order to make sure that all participants had similar knowledge about sleep hygiene practices, we discussed this topic during the first appointment in the hospital and we provided written instructions for sleep hygiene. The researcher also explained the procedures of the study and provided the stimuli for the classical conditioning (Figure 2).

\section{Design}

The study started on the first Sunday after the appointment in the hospital, with a baseline week in which parents completed questionnaires and daily sleep diaries, and children wore actometers. After a week, treatment started. All children started with a dose of $1 \mathrm{mg}$, fast-release melatonin. If parents did not see any effect of melatonin use after 4 days, they were allowed to increase the dose to $2 \mathrm{mg}$. If this still had no effect, the dose could be further increased every 4 days, until sleep onset advanced. Maximum dose was $5 \mathrm{mg}$. The procedure to increase the dose gradually in case of no effect was in accordance with recent clinical recommendations for prescribing melatonin in children, although they advise to start with an even lower dose $(0.2-0.5 \mathrm{mg}) .{ }^{9}$ However, this was not possible in our study, as all children had to respond to treatment within 3 weeks.

Table I Descriptive statistics of the experimental and comparison groups

\begin{tabular}{|c|c|c|c|}
\hline Variables & $\begin{array}{l}\text { Experimental group }(\mathbf{N}=16) \\
\text { Mean (SD) }\end{array}$ & $\begin{array}{l}\text { Comparison group }(\mathrm{N}=4 \mathrm{I}) \\
\text { Mean (SD) }\end{array}$ & $\begin{array}{l}\text { Test for significant difference } \\
t(d f), p\end{array}$ \\
\hline \multirow[t]{3}{*}{ Age (years) } & $9.92(1.64)^{\mathrm{a}}$ & $9.43(2.05)^{\mathrm{b}}$ & $0.86(55), 0.39$ \\
\hline & Frequency (\%) & Frequency (\%) & $p$-Value \\
\hline & & & Fisher's exact test \\
\hline Boys & $6(37.50)^{c}$ & $24(58.54)^{d}$ & 0.24 \\
\hline ADHD & $4(25.00)$ & $8(19.51)$ & 0.72 \\
\hline ASD & $0(0.00)$ & $5(12.20)$ & 0.31 \\
\hline ADHD and ASD & I (6.25) & I (2.44) & 0.49 \\
\hline ADHD medication & $4(25.00)$ & $4(9.76)$ & 0.20 \\
\hline Enuresis & $2(12.50)$ & $0(0.00)$ & 0.08 \\
\hline Complaints of headache & $3(18.75)$ & $0(0.00)$ & 0.02 \\
\hline
\end{tabular}

Notes: aln the subgroups of children with ADHD/autism and without ADHD/autism, the average age was 10.55 (I.24) years and 9.64 (I.77) years, respectively. ${ }^{b}$ In the subgroups of children with ADHD/autism and without ADHD/autism, the average age was 8.72 (I.75) years and 9.79 (2.13) years, respectively. CIn the subgroups of children with ADHD/autism and without ADHD/autism, the number of boys was $2(40.00 \%)$ and $4(36.36 \%)$, respectively. In the subgroups of children with ADHD/autism and without ADHD/autism, the number of boys was 9 (64.29\%) and 15 (55.56\%), respectively.

Abbreviations: ADHD, attention deficit hyperactivity disorder; ASD, Autism spectrum disorder; SD, standard deviation. 

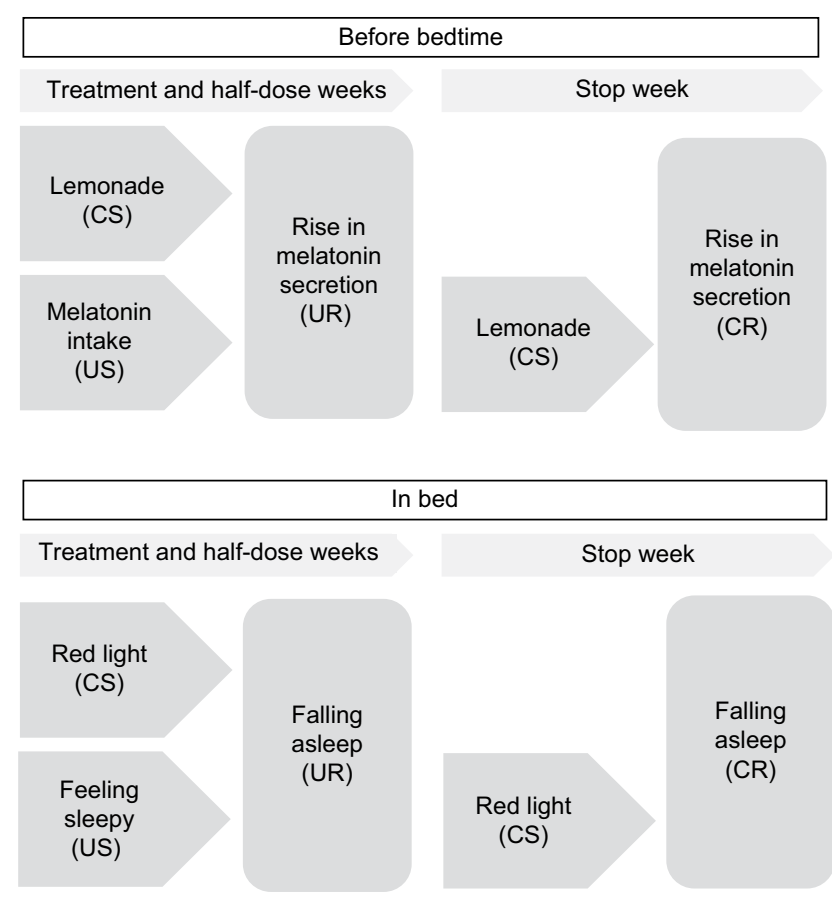

Figure 2 Classical conditioning procedure.

Notes: Conditioned stimuli were a biological lemonade with peppermint taste and a dim red light lamp with curly cord. Children were instructed to drink the lemonade (CS) at the moment that they took the melatonin tablet (US) to couple the lemonade to the rise in melatonin secretion (UR) and making the lemonade a CS for melatonin secretion (CR). The red light (CS) was turned on when the child went to bed and felt sleepy (US) to couple the red light to falling asleep (UR) and making it a CS for falling asleep (CR). Parents were instructed to switch the red light off when the child got up in the morning.

Abbreviations: CS, conditioned stimulus; US, unconditioned stimulus; UR, unconditioned response; $\mathrm{CR}$, conditioned response.

After 3 weeks of melatonin treatment, parents filled in the questionnaires and children chewed on the cotton plugs. Then treatment was discontinued by first taking a half dose for 1 week (hereafter called the "half-dose week") and then stopping completely for another week (hereafter called the "stop week"). After this stop week, we repeated the assessments. Parents filled in sleep diaries and children wore actometers during this whole period of 6 weeks. The stimuli were used during the 3 treatment weeks, the half-dose week, and the stop week. Families received reminders through text messages or emails on days that questionnaires had to be filled in, children had to chew on cotton plugs, melatonin dose had to be halved or treatment had to be discontinued. In addition, all families were contacted by telephone twice during this study to discuss their experiences: once in the first week of treatment and once after the end of the stop week. Children were allowed to recommence with melatonin after the last day of the stop week.

The study consisted of three measurements (Figure 1): baseline (in the week before the start of treatment; T0), directly after 3 weeks of treatment (T1), and at the end of the stop week (T2). At these measurement occasions, DLMO was determined in saliva and questionnaires were filled in.
Participants in the previous study ${ }^{13}$ served as comparison group. They went through the same procedures, with the same measurements, except for the baseline sleep measurements (sleep diaries and actigraphy) and the use of stimuli for classical conditioning.

\section{Measures}

The same variables were measured in both groups, but different questionnaires were used to measure behavior problems in the experimental and comparison groups.

\section{Sleep}

Parents filled in sleep diaries daily via Internet. The sleep diary consisted of questions concerning bed time, lights off time, sleep onset time, and questions on whether the child woke up during the night. Sleep latency (time children spent in bed before falling asleep) and sleep start were used as sleep variables in the analyses.

In addition to sleep diaries, sleep was measured with AW4 acti-watches (Cambridge Neurotechnology Ltd, Cambridge, UK). Children were instructed to wear the actigraph on their nondominant wrist when they went to bed and to remove it in the morning when they got out of bed. The actometers were used to obtain objective information about sleep latency, sleep start, total sleep time (time children actually slept during the night), and sleep efficiency (total sleep time/time in bed). Nocturnal activity data were logged at $1 \mathrm{~min}$ epochs and scored with the Actiwatch Sleep Analysis 7 software (Cambridge Neurotechnology Ltd).

\section{DLMO}

DLMO, which can be used as an indication of the timing of the biological clock, was measured in saliva using Bühlmann RIA kits (Bühlmann, Schönenbuch, Switzerland). Children chewed on cotton plugs hourly from 19:00 to 23:00 $\mathrm{h}$ in the evening at dim light. ${ }^{11,15}$ DLMO was operationalized as the clock time at which the endogenous melatonin secretion reached the threshold of $4 \mathrm{pg} / \mathrm{mL} .{ }^{28,29}$ Radioimmunoassay was used to analyze saliva samples. ${ }^{30,31}$ Children were not allowed to use melatonin in the evenings when DLMO was measured.

\section{Health}

The health status of the children was measured with the first part of the functional status II (FSII). ${ }^{32,33}$ This first part consists of 14 items concerning activities and behaviors in the past 2 weeks. An example of an item is "Did your child seem to feel sick and tired?" Parents had to indicate how often these behaviors or activities occurred on a three-point scale varying from (0) "never or rarely" to (1) "some of the 
time" and (2) "almost always". A higher score indicates a better functional status and consequently a better health. Cronbach's alpha varied between 0.80 and 0.93 at the different measurement occasions.

\section{Parenting stress}

Parenting stress was measured with the Nijmegen Parental Stress Index short version (NOSIK). ${ }^{34}$ The NOSIK is a questionnaire with 17 items that measures to what extent parents experience stress in parenting their child. An example of an item is "My child often demands more attention than I can give". Parents answered the items on a 4-point scale, ranging from (1) "strongly disagree" to (4) "strongly agree". A higher score indicated more parenting stress. Reliability varied from 0.93 to 0.96 .

\section{Behavior problems}

Behavior problems were operationalized differently in the experimental and comparison groups and could thus not be compared across groups.

In the experimental group, behavior problems in children were measured with the Strength and Difficulties Questionnaire (SDQ) ${ }^{35,36}$ This questionnaire has 25 items asking about various child behaviors, for example, "often loses temper". Response options are (1) "not true", (2) "somewhat true", and (3) "certainly true". The following subscales are distinguished: emotional symptoms, conduct problems, hyperactivity/inattention, peer relationship problems, and prosocial behavior. The first four scales together yield a total problem behavior score. Cronbach's alpha varied between 0.88 and 0.91 at the different measurement occasions.

In the comparison group, behavior problems were measured with the Child Behavior Checklist (CBCL). ${ }^{37,38}$ The CBCL is a comprehensive (112 items) questionnaire. An example of an item is "temper tantrums or hot temper". The response scale ranged from (0) "not true" to (2) "very true or often true", with a higher score indicating more behavior problems. The reliability varied from 0.95 to 0.96 at the different measurement occasions.

\section{Statistical analysis}

Data were analyzed using linear mixed models in SPSS, treating the repeated observations as nested within children. In this way, all available data were used to answer the research questions, including data from children with missing observations. For the sleep variables, it was first determined which longitudinal structure best described the variances and covariances of the 41 daily assessments. ${ }^{39}$ For all sleep variables, a first-order autoregressive covariance structure was chosen.
For the questionnaire data that were collected at three measurement occasions, free covariance structures were used.

Outcome variables were sleep variables measured during the different phases of the treatment (baseline week, treatment weeks, half-dose week, and stop week) and DLMO and sum scores for the different questionnaires measured at T0 through T2. In the sleep data analyses, treatment days for which parents reported that no melatonin was taken (forgotten or on purpose) were omitted from the analyses. In addition, in several cases children used melatonin before the end of the stop week. These days were also omitted as to prevent distortion of the effects.

Changes in sleep were investigated by testing main effects of treatment phases as explanatory variables. Each of the linear mixed models included indicator variables for baseline week, half-dose week, and stop week. By leaving out an indicator variable for treatment weeks, the treatment weeks serve as a reference, and the regression coefficients represent mean differences between measurements during treatment weeks and measurements during baseline week, half-dose, and stop weeks. We also included indicator variables for weekend measurements to control for weekend effects that may otherwise bias the estimates of treatment effects.

Differences between the experimental and comparison groups were investigated by testing the main effects of group membership as an explanatory variable. Each model included an indicator variable for group membership; coded 1 for children in the experimental group (with conditioning) and 0 for children in the comparison group (without conditioning), so that the associated regression coefficient represents the mean difference between the experimental and control groups on the outcome variables.

To answer the main research question, whether the effects of discontinuing melatonin treatment are different for the experimental and comparison groups, we tested interaction effects between treatment phases and group. Significant interaction effects of "half dose $\times$ conditioning" and "stop week $\times$ conditioning" would indicate that the effects of discontinuing melatonin treatment are different for the experimental "conditioning" group and the comparison "no conditioning" group, and thus imply an effect of classical conditioning.

The linear mixed models also included an indicator variable for ADHD/autism, in order to test the main effects of $\mathrm{ADHD} /$ autism, the interaction effects of $\mathrm{ADHD} /$ autism $\times$ group membership, ADHD/autism $\times$ treatment phases, and the second-order interaction effect $\mathrm{ADHD}$ /autism $\times$ group membership $\times$ treatment phases. A significant second-order interaction effect would mean that classical conditioning has differential effects for children with or without ADHD/autism. 
Similar linear mixed models were used to test the effects on DLMO and on the outcomes that were measured through questionnaires. These models included main effects of measurement occasions, group status, and ADHD/autism. We also included interaction effects between measurement occasions, group and ADHD/autism, and second-order interaction effects of $\mathrm{ADHD} /$ autism $\times$ group status $\times$ measurement occasions. A significant interaction effect of stop week and group would indicate an effect of classical conditioning, and a significant second-order interaction would indicate that there are different effects of classical conditioning for children with ADHD and/or autism.

All outcome variables in the linear mixed modeling were standardized, and all explanatory variables were binary coded (ie, 0 or 1 ), so that all regression coefficients can be interpreted according to Cohen's ${ }^{40}$ rules of thumb for effect size $d$, with $0.2,0.5$, and 0.8 indicating "small", "medium", and "large" effect sizes. The regression effects are additive. For example, to obtain the expected total effect of conditioning in the stop week, one must add the regression coefficients of the main effect of "stop week", the main effect of conditioning (group), and the interaction effect of stop week $\times$ conditioning. And to obtain the expected total effect of conditioning for a child with ADHD in the stop week, one must additionally add the main and interaction effects of "ADHD/autism" (see the description of the effects on sleep latency [sleep diary] for an example).

\section{Ethical standards}

All procedures performed in studies involving human participants were in accordance with the Declaration of Helsinki (1964). The study was approved by the Ethical Committee of the Research Institute of Child Development and Education, University of Amsterdam. Informed consent was obtained from all individual participants included in the study.

\section{Results}

\section{Dose of melatonin and time of administration}

All participants took melatonin at 19:00 h. The majority of children took $1 \mathrm{mg}$ melatonin $(66.7 \%$ in the experimental group and $61 \%$ in the comparison group). Mean (standard deviation [SD]) dose in the experimental and comparison groups was $1.6(1.1)$ and $1.5(1.0) \mathrm{mg}$, respectively.

\section{Sleep outcomes}

Mean and SD of all variables for the different measurement occasions are reported in Table 2 for the experimental vs. comparison groups and in Table 3 for the children in the experimental group with vs. without ADHD/autism.

\section{Sleep diary}

Results of the linear mixed models analyses showed that sleep latency reduced during melatonin treatment, as latency was significantly longer during baseline $\left(\beta_{\text {baseline }}=0.71, p<0.01\right.$; Table 4). In the half-dose week, sleep latency increased compared to treatment $\left(\beta_{\text {half dose }}=0.21, p=0.02\right)$, but not for children with $\mathrm{ADHD} /$ autism $\left(\beta_{\text {half dose } \times \mathrm{ADHD} / \text { autism }}=-0.37, p=0.01\right.$; we note that the regression coefficients are additive, so for ADHD children the expected total effect in the half-dose week is $\beta_{\text {half dose }}+\beta_{\mathrm{ADHD} / \text { autism }}+\beta_{\text {half dose } \times \mathrm{ADHD} / \mathrm{autism}}=0.21-0.18$ $-0.37=-0.34)$. During the stop week, sleep latency was longer compared to treatment $\left(\beta_{\text {stop week }}=0.91, p<0.01\right)$, but the increase was less for children in the experimental group $\left(\beta_{\text {stop week } \times \text { conditioning }}=-0.39, p=0.03\right.$; the total effect is $\beta_{\text {stop week }}$ $+\beta_{\text {conditioning }}+\beta_{\text {stop week } \times \text { conditioning }}=0.91-0.20-0.39=0.32$ ). The latter result indicates an effect of classical conditioning. However, this was only true for children without ADHD/ autism, as a significant second-order interaction indicated that for children with ADHD/autism in the experimental group sleep latency increased more in the stop week, so for them classical conditioning was counterproductive $(\beta=0.96$, $p<0.01$; total effect is $0.91-0.20-0.39-0.18+0.97-0.19$ $+0.96=1.88)$.

In addition, we found a main effect of weekend $(\beta=-0.14$, $p<0.01)$, indicating that sleep latency was shorter during weekends. A significant interaction effect between group and ADHD/autism $(\beta=0.97, p=0.01)$ indicated that children with $\mathrm{ADHD} /$ autism in the experimental group had longer sleep latencies during treatment (total effect is $-0.20-0.18+$ $0.97=0.59$ ). The effects are illustrated in Figure $3 \mathrm{~A}$.

Sleep start was significantly earlier during melatonin treatment compared to baseline. During the half-dose week and stop week, sleep start was later than during melatonin treatment, although for children with ADHD/autism in the comparison group, sleep start did not increase during half-dose week and the increase in the stop week was less strong. There was an effect of classical conditioning, as the interaction effect of group and stop week showed that for the experimental group, sleep start delayed less in the stop week. However, a second-order interaction indicated that for children with ADHD/autism in the experimental group, sleep start increased in the stop week, which suggests that for these children classical conditioning was counterproductive (Table 4 and Figure 3B). In addition, there was a main effect of weekend, indicating that sleep start was later during weekends. 

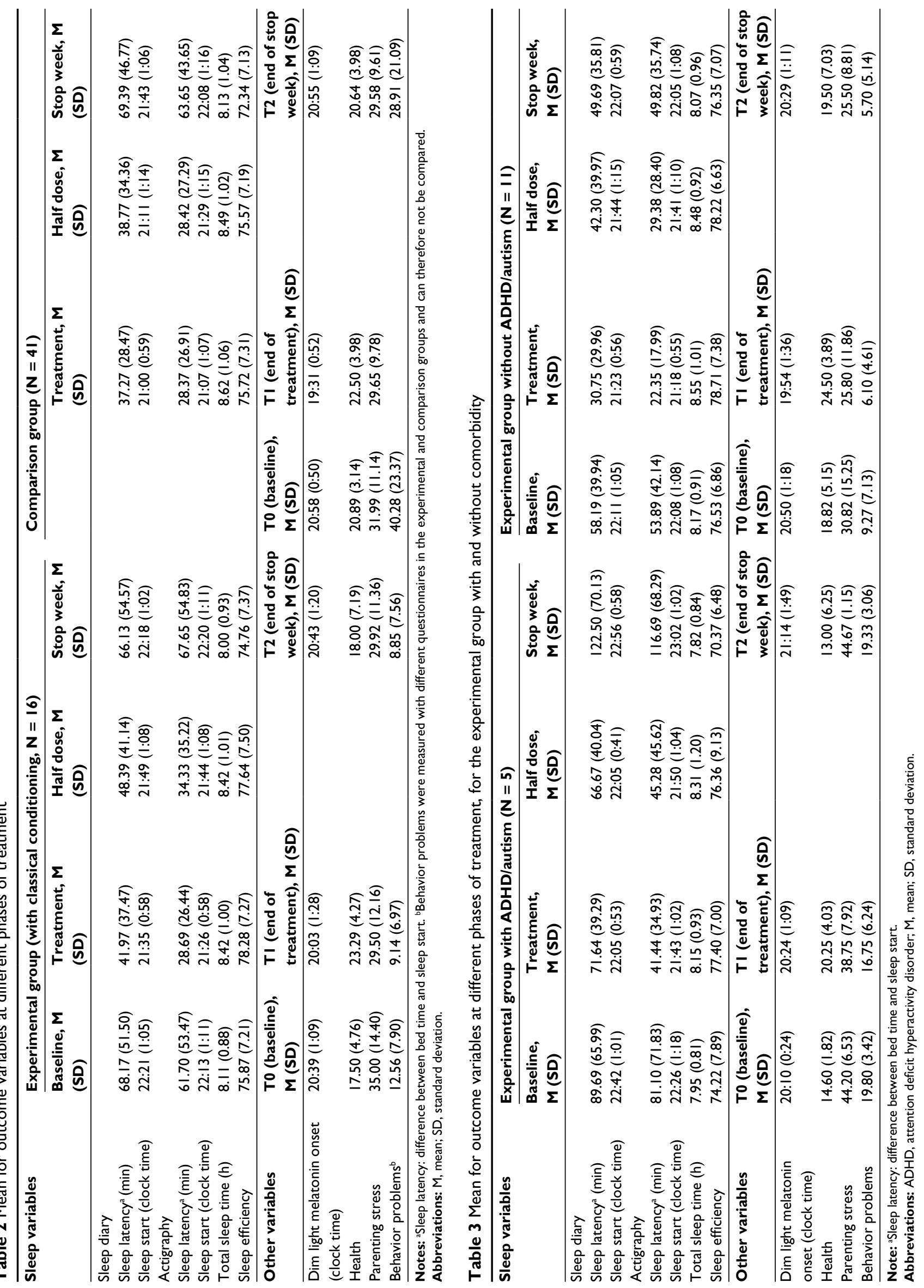


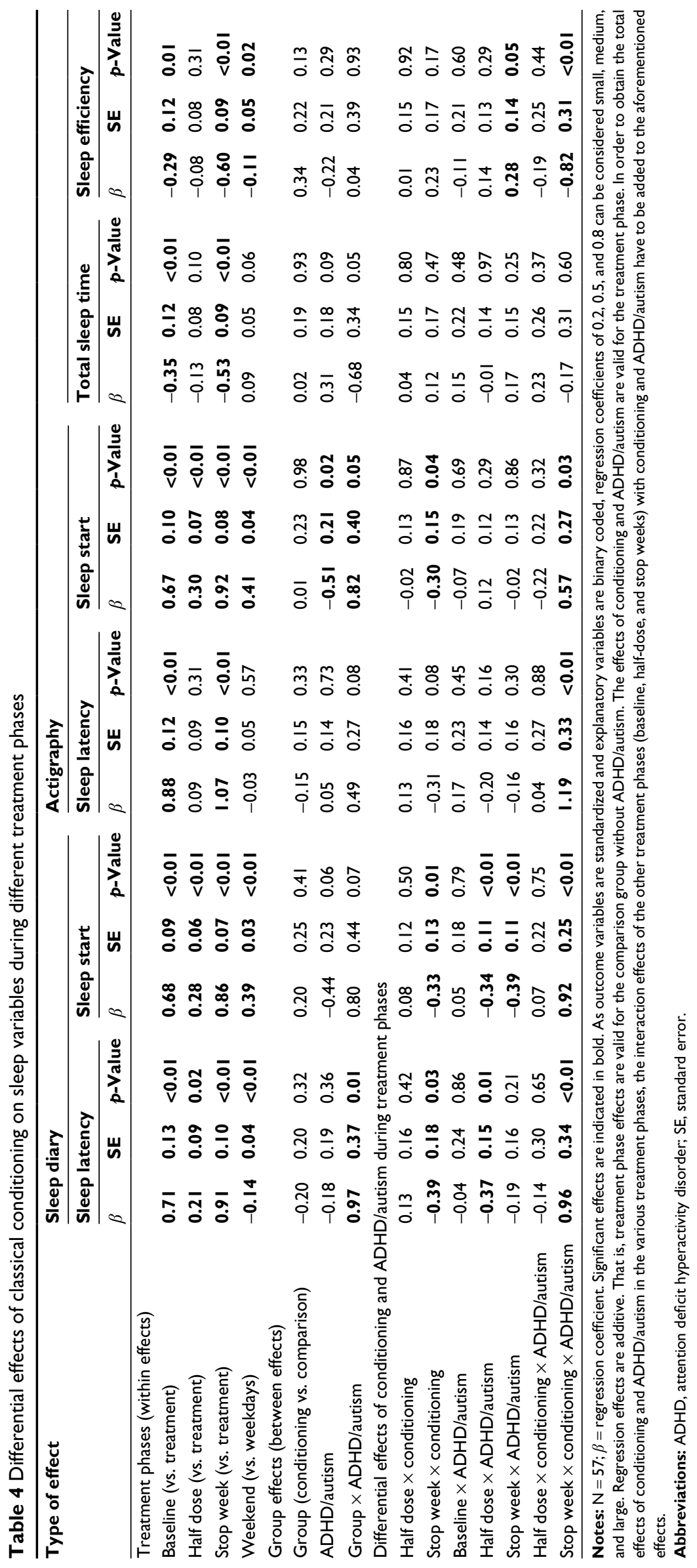


A

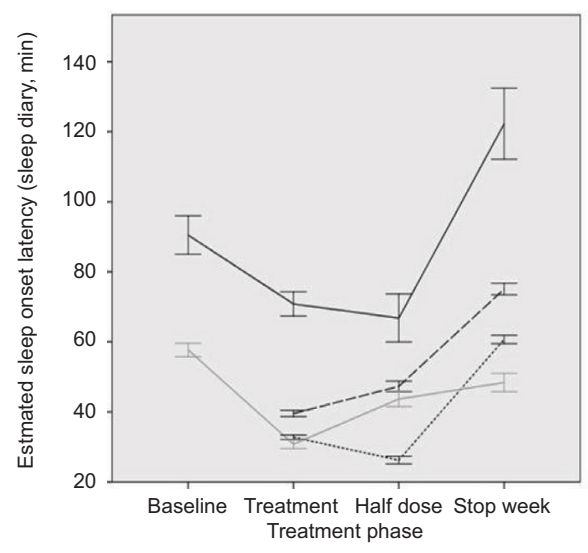

C

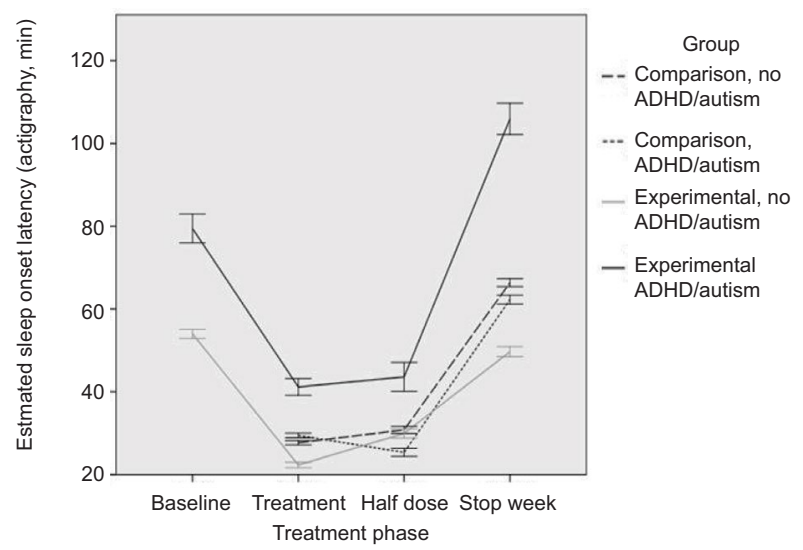

E

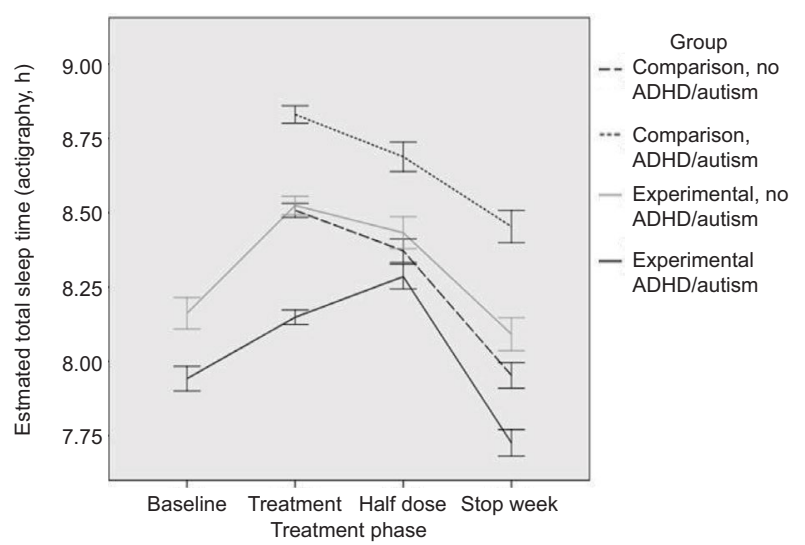

B

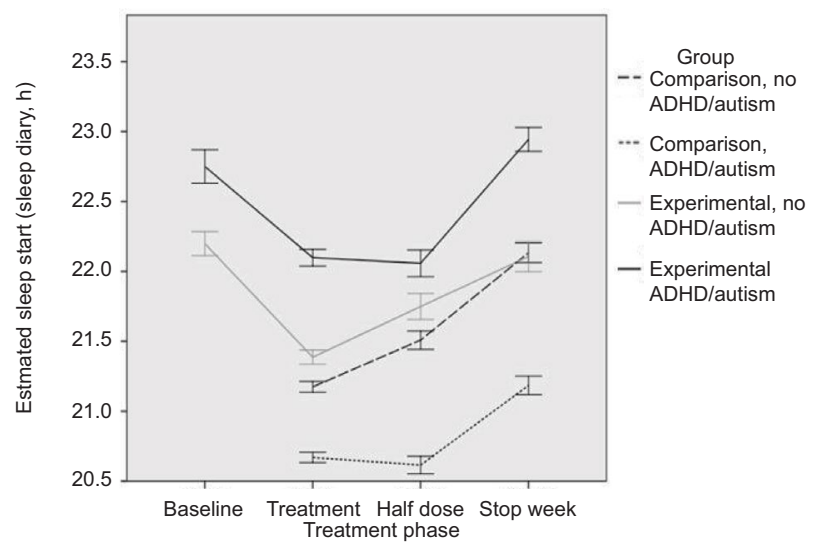

D

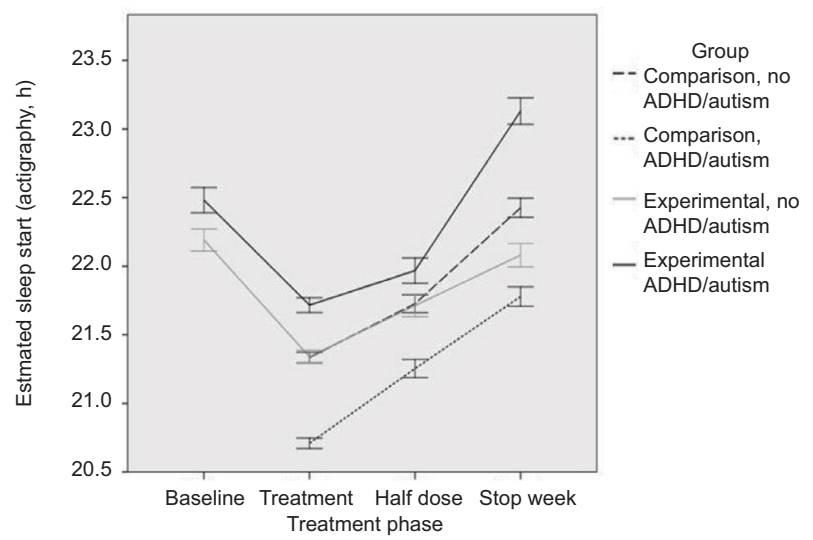

$\mathbf{F}$

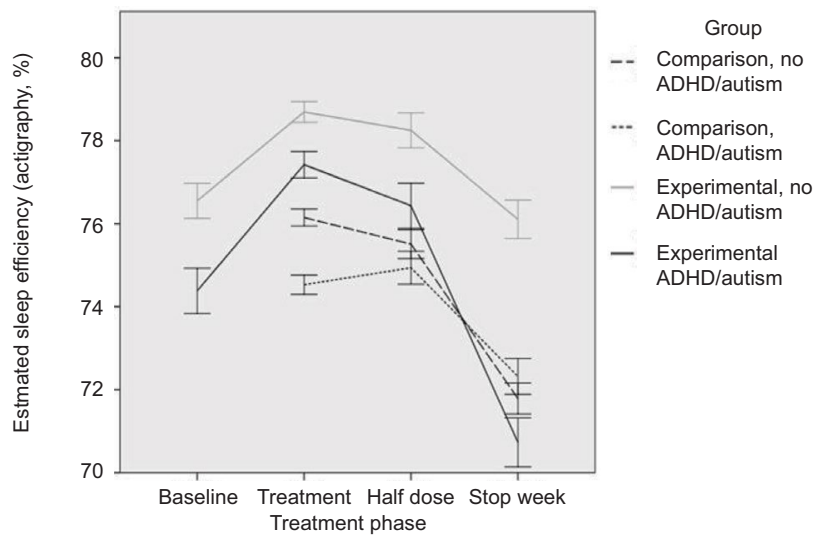

Figure 3 Average sleep scores in different treatment phases by group and ADHD/autism diagnosis.

Notes: A Sleep onset latency (sleep diary); B sleep start (sleep diary); C sleep onset latency (actigraphy); D sleep start (actigraphy); E total sleep time (actigraphy); F sleep efficiency (actigraphy).

Abbreviation: $A D H D$, attention deficit hyperactivity disorder.

\section{Actigraphy}

Sleep latency was significantly reduced during melatonin treatment compared to baseline, and this was still true during the half-dose week. During the stop week, sleep latency was significantly longer than during melatonin treatment. There were no significant interaction effects between group and treatment phases, indicating that the treatment effects were not different for the two groups and there was no effect of classical conditioning. However, there was a significant second-order interaction effect, indicating that for children with $\mathrm{ADHD}$ /autism in the experimental group, sleep latency increased more in the stop week (Figure 3C).

Sleep start was significantly earlier during melatonin treatment compared to baseline. During the half-dose week and the stop week, sleep start was significantly later than during melatonin treatment. For the experimental group, sleep 
start delayed less in the stop week (which shows an effect of classical conditioning), but for children with ADHD/autism in the experimental group, sleep start increased more in the stop week (Figure 3D). There were main effects for ADHD/ autism and weekend, indicating that in the comparison group children with ADHD/autism had an earlier sleep start during treatment, and that sleep start was later during weekends. Also, children with ADHD/autism in the experimental group fell asleep later during treatment.

Total sleep time was longer during melatonin treatment compared to baseline. During the stop week, total sleep time was shorter than during melatonin treatment. For total sleep time, no effect of classical conditioning was found (Figure 3E).

Sleep efficiency was higher during melatonin treatment compared to baseline. During the stop week, sleep efficiency was lower than during melatonin treatment, but for children with ADHD/autism in the comparison group, the decrease in sleep efficiency in the stop week was less strong. No effect of classical conditioning was found, but the significant secondorder interaction showed that for children with ADHD/autism in the experimental group, sleep efficiency decreased more in the stop week (Table 4 and Figure 3F). Sleep efficiency was generally lower during the weekends.

\section{Other variables}

DLMO significantly advanced during melatonin treatment, but this was no longer the case after the stop week. There were no significant interaction effects of group with measurement occasions. Health improved after melatonin treatment, but this positive effect disappeared after the stop week. A significant interaction effect indicated that children with ADHD/autism in the experimental group had worse health scores. All participants scored higher on health after treatment, especially the experimental group. Parenting stress did not significantly change but was higher for parents of a child with ADHD/autism.

Behavior problems decreased after melatonin treatment in the experimental group, and this was still true after the stop week. Children with ADHD/autism scored higher on behavior problems. As different questionnaires were used in the experimental and comparison groups, the results could not be compared between the two groups, but in the comparison group, the reduction in behavior problems after treatment also remained after the stop week. ${ }^{13}$ Results are shown in Table 5.

\section{Discussion}

This pilot study shows that melatonin treatment advanced DLMO and sleep onset, improved parent-reported health, and reduced behavior problems in children with chronic sleep onset problems related to a delayed DLMO. However, most treatment effects disappeared after melatonin treatment was discontinued. Only for sleep latency (according to parent report) and sleep start (according to both parent report and actigraphy), we found that sleep deterioration in the stop week was less strong for the experimental group, which suggests an effect of classical conditioning.

When controlling for ADHD/autism, we found that sleep deterioration in the stop week in many cases was stronger for children with ADHD/autism in the experimental group. This

Table 5 Treatment effects on DLMO, sleep quality, health, behavior problems, and parenting stress

\begin{tabular}{|c|c|c|c|c|c|c|c|c|c|c|c|c|}
\hline \multirow[t]{2}{*}{ Type of effect } & \multicolumn{3}{|c|}{ DLMO } & \multicolumn{3}{|c|}{ Health } & \multicolumn{3}{|c|}{ Parenting stress } & \multicolumn{3}{|c|}{ Behavior problems ${ }^{\mathbf{a}}$} \\
\hline & $\beta$ & SE & p-Value & $\beta$ & SE & p-Value & $\beta$ & SE & p-Value & $\beta$ & SE & p-Value \\
\hline \multicolumn{13}{|l|}{ Measurement occasions (within effects) } \\
\hline Treatment vs. baseline & -1.32 & 0.19 & $<0.01$ & 0.40 & 0.18 & 0.03 & -0.14 & 0.12 & 0.22 & -0.35 & 0.16 & 0.04 \\
\hline Stop week vs. baseline & -0.16 & 0.19 & 0.42 & 0.03 & 0.22 & 0.87 & -0.16 & 0.12 & 0.18 & -0.40 & 0.11 & $<0.01$ \\
\hline \multicolumn{13}{|l|}{ Group effects (between effects) } \\
\hline Group (conditioning vs. comparison) & -0.23 & 0.26 & 0.39 & -0.43 & 0.27 & 0.12 & 0.22 & 0.35 & 0.54 & & & \\
\hline ADHD/autism & -0.36 & 0.24 & 0.14 & 0.09 & 0.25 & 0.74 & 0.95 & 0.32 & $<0.01$ & 1.40 & 0.42 & $<0.01$ \\
\hline Group $\times$ ADHD/autism & -0.14 & 0.49 & 0.78 & -1.02 & 0.48 & 0.04 & 0.28 & 0.62 & 0.65 & & & \\
\hline \multicolumn{13}{|c|}{ Differential effects of conditioning and ADHD/autism during treatment phases } \\
\hline Treatment $\times$ conditioning & 0.50 & 0.37 & 0.18 & 0.81 & 0.33 & 0.02 & -0.11 & 0.22 & 0.61 & & & \\
\hline Stop week $\times$ conditioning & -0.19 & 0.41 & 0.64 & 0.06 & 0.40 & 0.88 & -0.14 & 0.22 & 0.52 & & & \\
\hline Treatment $\times$ ADHD/autism & 0.26 & 0.34 & 0.44 & -0.13 & 0.30 & 0.67 & -0.20 & 0.19 & 0.31 & -0.09 & 0.29 & 0.76 \\
\hline Stop week $\times$ ADHD/autism & 0.18 & 0.34 & 0.59 & -0.31 & 0.36 & 0.39 & -0.25 & 0.20 & 0.21 & 0.21 & 0.21 & 0.34 \\
\hline Treatment $\times$ group $\times$ ADHD/autism & 0.66 & 0.69 & 0.34 & 0.19 & 0.60 & 0.76 & -0.02 & 0.39 & 0.97 & & & \\
\hline Stop week $\times$ group $\times$ ADHD/autism & 1.00 & 0.77 & 0.20 & -0.13 & 0.77 & 0.87 & 0.51 & 0.41 & 0.23 & & & \\
\hline
\end{tabular}

Notes: $\beta=$ regression coefficient. As outcome variables are standardized and explanatory variables are binary coded, regression coefficients of $0.2,0.5$, and 0.8 can be considered small, medium, and large. Significant effects are indicated in bold. ${ }^{a}$ For behavior problems only results for the experimental group are reported.

Abbreviations: ADHD, attention deficit hyperactivity disorder; SE, standard error; DLMO, dim light melatonin onset. 
suggests that classical conditioning is counterproductive in children with ADHD/autism. A possible explanation for the stronger deterioration of children with ADHD/autism in the experimental group is that proportionally more children with ADHD/autism (4 of 5) in the experimental group than in the comparison group (4 of 14) received methylphenidate, which is found to negatively impact sleep. ${ }^{41}$ In our analyses, we operationalized comorbidity with a control variable for ADHD and autism combined, as the small sample size did not permit to include two separate variables. However, we further investigated the idea that comorbidity in general, or medication use in children with ADHD specifically, might deteriorate the effect of classical conditioning by repeating our analyses in two ways. 1) After excluding children diagnosed with autism, and 2) after also excluding children diagnosed with ADHD but not using medication, but this did not change our results.

Remarkably, children with ADHD/autism in the experimental group had a later sleep start and shorter total sleep time than children with ADHD/autism in the comparison group, which is probably due to the 2-year age difference between these two groups (10.6 vs. 8.7 years, respectively). However, it should also be noted that due to the small group sizes, individual children had a large impact on the results. For example, one of the children with ADHD in the experimental group slept extremely bad without melatonin, which had a strong impact on the average scores of this small group.

Interestingly, we found that an improvement in children's sleep coincides with an improvement in their health and behavior. The effects on behavior problems remained after the stop week. As the stop week was only 1 week, it is possible that the positive effects will disappear when treatment is discontinued for a longer time. Although it would be interesting to investigate this hypothesis in future research, it might be difficult to gain the cooperation of parents and children, because they often want to continue melatonin treatment as soon as possible when the positive effects on sleep disappear.

There are several possible explanations for the fact that we did not find larger effects of classical conditioning in children without comorbidity. One explanation could be that the period of conditioning in our study (4 weeks) was too short. Another explanation is that the timing of the stimuli that we used was not suitable. The drink was taken at the same time the melatonin was taken, because we aimed to condition the drink to the physiological reaction that the intake of melatonin induces (ie, rise in melatonin secretion), following the studies of Evans and Bond ${ }^{25}$ and Poser et al. ${ }^{26}$
However, in these studies methohexitone was used, which almost immediately induced sleep. Melatonin does not work that fast. At the time children took the melatonin, they were still feeling awake. It might be that herewith the drink was coupled to the feeling of being awake, instead of to the physiological response as we intended. The timing of the lamp was probably better as children felt sleepy when they went to bed, but as we do not know any studies that used a lamp as CS, we do not have any evidence for the effectiveness of this kind of stimulus. A lamp is very different from counting or listening to the ticking of a metronome as was used as stimulus in the previous studies, ${ }^{25,26}$ which demands a more attentive role of the person. Perhaps a stimulus requiring involvement of the person would have a better effect.

This study has several strengths, such as daily assessments of sleep in a time-series design with multiple cases and comparison group, the use of objective sleep measurements, and a naturalistic setting. However, there are also some important limitations inherent to the fact that this was a pilot study. First, we should note that the sample in the experimental study was small, and that some of the children resumed melatonin treatment during the stop week already. However, due to the large number of observations per child, the effective sample size was still sufficient to find significant effects.

We should also note that this study did not include a real control group but used a comparison group that participated in a previous study. However, apart from the fact that significantly more children in the experimental group complained of headache compared to the control group, there were no significant differences in baseline characteristics between the groups. Another limitation is that the experimental group was studied in spring and the comparison group in the fall. Although melatonin was found to be effective in both groups, we cannot ignore the possibility that longer light exposure also had an adverse effect on sleep after discontinuation of treatment in the experimental group. We did not check the effect of the sleep hygiene instructions. However, sleep hygiene instructions provided were the same in the experimental and comparison groups, so we do not have any indication to suspect that effect of sleep hygiene instructions would differ between the groups.

\section{Conclusion}

The present pilot study is the first study investigating the effects of classical conditioning in preserving effects of melatonin treatment. The results of this study indicate that there might be some effects of classical conditioning of melatonin treatment in children with sleep onset problems 
related to delayed melatonin onset, but only for children without comorbid ADHD or autism. We therefore believe it is important to further investigate the effectiveness of classical conditioning of melatonin use in children without comorbid ADHD or autism. For future research, we would recommend to study larger, more homogeneous samples to use other stimuli, preferably more specifically directed at the time of falling asleep and to vary the duration of both melatonin treatment and the period of classical conditioning. In addition, it would be advisable to add bright light in the morning in order to try to enlarge treatment effects..$^{20,42,43}$

\section{Acknowledgments}

The authors thank Jip Jansma and Linda van der Ven for their help in the data collection.

The abstract of this research has been published in SLEEP-WAKE Research in the Netherlands, Volume 26, 2015, and has been published online: http://www.nswo. nl/userfiles/files/publications/Jaarboek-2015/NSWO $\% 20$ Jaarboek $\% 202015$.pdf. In addition, the research was presented at the 22nd Congress of the European Sleep Research Society in Tallinn, Estonia, September 2014, and its abstract was published in Journal of Sleep Research, Volume 23 (Supplement 1).

\section{Disclosure}

The authors report no conflicts of interest in this work.

\section{References}

1. Fricke-Oerkermann L, Plück J, Schredl M, et al. Prevalence and course of sleep problems in childhood. Sleep. 2007;30(10):1371-1377.

2. Spruyt K, O'Brien LM, Cluydts R, Verleye GB, Ferri R. Odds, prevalence and predictors of sleep problems in school-age normal children. J Sleep Res. 2005;14(2):163-176.

3. Dewald JF, Meijer AM, Oort FJ, Kerkhof GA, Bögels SM. The influence of sleep quality, sleep duration and sleepiness on school performance in children and adolescents: a meta-analytic review. Sleep Med Rev. 2010;14(3):179-189.

4. Fallone G, Owens JA, Deane J. Sleepiness in children and adolescents: clinical implications. Sleep Med Rev. 2002;6(4):287-306.

5. Gregory AM, O'Connor TG. Sleep problems in childhood: a longitudinal study of developmental change and association with behavioral problems. J Am Acad Child Adolesc Psychiatry. 2002;41(8):964-971.

6. Gregory AM, Caspi A, Eley TC, Moffitt TE, O'Connor TG, Poulton R. Prospective longitudinal associations between persistent sleep problems in childhood and anxiety and depression disorders in adulthood. J Abnorm Child Psychol. 2005;33(2):157-163.

7. Borbély AA, Daan S, Wirz-Justice A, Deboer T. The two-process model of sleep regulation: a reappraisal. J Sleep Res. 2016;25(2):131-143.

8. Brzezinski A. Melatonin in humans. NEnglJMed. 1997;336(3):186-195.

9. Bruni O, Alonso-Alconada D, Besag F, et al. Current role of melatonin in pediatric neurology: clinical recommendations. Eur J Paediatr Neurol. 2015;19(2):122-133.

10. Smits MG, Nagtegaal EE, van der Heijden J, Coenen AM, Kerkhof GA. Melatonin for chronic sleep onset insomnia in children: a randomized placebo-controlled trial. J Child Neurol. 2001;16(2):86-92.
11. Smits MG, van Stel HF, van der Heijden KB, Meijer AM, Coenen AML, Kerkhof GA. Melatonin improves health status and sleep in children with idiopathic chronic sleep-onset insomnia: a randomized placebocontrolled trial. J Am Acad Child Adolesc Psychiatry. 2003;42(11): 1286-1293.

12. Van Geijlswijk IM, Korzilius HP, Smits MG. The use of exogenous melatonin in delayed sleep phase disorder: a meta-analysis. Sleep. 2010;33(12):1605-1614.

13. Van Maanen A, Meijer AM, Smits MG, Oort FJ. Termination of short term melatonin treatment in children with delayed Dim Light Melatonin Onset: effects on sleep, health, behavior problems, and parenting stress. Sleep Med. 2011;12(9):875-879.

14. Rossignol DA, Frye RE. Melatonin in autism spectrum disorders: a systematic review and meta-analysis. Dev Med Child Neurol. 2011;53(9):783-792.

15. Van der Heijden KB, Smits MG, van Someren EJW, Ridderinkhof R, Gunning B. Effect of melatonin on sleep, behavior, and cognition in ADHD and chronic sleep-onset insomnia. $J$ Am Acad Child Adolesc Psychiatry. 2007;46(2):233-241.

16. Johnson KP, Giannotti F, Cortesi F. Sleep patterns in autism spectrum disorders. Child Adolesc Psychiatr Clin North Am. 2009;18: 917-928.

17. Stein MA. Unravelling sleep problems in treated and untreated children with ADHD. J Child Adolesc Psychopharmacol. 1999;9(3): $157-168$.

18. Sung V, Hiscock H, Sciberras E, Efron D. Sleep problems in children with attention-deficit/hyperactivity disorder: prevalence and the effect on the child and family. Arch Pediatr Adolesc Med. 2008;162(4):336-342.

19. Williams PG, Sears LL, Allard A. Sleep problems in children with autism. J Sleep Res. 2004;13(3):265-268.

20. Burke TM, Markwald RR, Chinoy ED, et al. Combination of light and melatonin time cues for phase advancing the human circadian clock. Sleep. 2013;36(11):1617-1624.

21. Carr R, Wasdell MB, Hamilton D, et al. Long-term effectiveness outcome of melatonin therapy in children with treatment-resistant circadian rhythm sleep disorders. J Pineal Res. 2007;43(4):351-359.

22. Hoebert M, van der Heijden KB, van Geijlswijk IM, Smits MG. Longterm follow-up of melatonin treatment in children with ADHD and chronic sleep onset insomnia. J Pineal Res. 2009;47(1):1-7.

23. Van Geijlswijk IM, Mol RH, Egberts TCG, Smits MG. Evaluation of sleep, puberty and mental health in children with long-term melatonin treatment for chronic idiopathic childhood sleep onset insomnia. Psychopharmacology. 2011;216(1):111-120.

24. Pavlov IP. Conditioned Reflexes. Oxford: Oxford University Press; 1927.

25. Evans DR, Bond IK. Reciprocal inhibition therapy and classical conditioning in the treatment of insomnia. Behav Res Ther. 1969;7(3): 323-325.

26. Poser EG, Fenton GW, Scotton L. The classical conditioning of sleep and wakefulness. Behav Res Ther. 1965;3(4):259-264.

27. Vits S, Cesko E, Enck P, Hillen U, SchadendorfD, Schedlowski M. Behavioral conditioning as the mediator of placebo responses in the immune system. Philos Trans R Soc B Biol Sci. 2011;366(1572):1799-1807.

28. Carskadon MA, Acebo C, Richardson GS, Tate BA, Seifer R. An approach to studying circadian rhythms of adolescent humans. $J$ Biol Rhythms. 1997;12(3):278-289.

29. Crowley SJ, Suh C, Molina TA, Fogg LF, Sharkey KM, Carskadon MA. Estimating the dim light melatonin onset of adolescents within a 6-h sampling window: the impact of sampling rate and threshold method. Sleep Med. 2016;20:59-66.

30. Nagtegaal E, Peeters T, Swart W, Smits M, Kerkhof G, van der Meer G. Correlation between concentrations of melatonin in saliva and serum in patients with delayed sleep phase syndrome. Ther Drug Monit. 1998; 20(2):181-183.

31. Van Maanen A, Meijer AM, Smits MG, van der Heijden KB, Oort FJ. Effects of melatonin and bright light treatment in childhood chronic sleep onset insomnia with late melatonin onset: a randomised controlled study. Sleep. Epub 2016 Oct 10. 
32. Post MWM, Kuyvenhoven MM, Verheij TJM, de Melker RA, Hoes AW. De Nederlandse 'Functional Status II (R)': een vragenlijst voor het meten van de functionele gezondheidstoestand van kinderen. [The Dutch 'Functional Status II (R)': a questionnaire for the measurement of the functional health status of children]. Ned Tijdschr Geneeskd. 1998;142:2675-2679. Dutch.

33. Stein REK, Jessop DJ. Functional status II(R): a measure of child health status. Med Care. 1990;28(11):1041-1055.

34. De Brock AJLL, Vermulst AA, Gerris JRM, Abidin RR. Nijmeegse ouderlijke stress index: meetinstrument voor de vaststelling van stress bij opvoeders: een uitgebreide versie (NOSI) voor psychodiagnostische doeleinden en een verkorte versie (NOSIK) voor signaleringsdoeleinden. [Nijmegen parental stress index: instrument for determining stress in parents: a comprehensive version (NOSI) for psychodiagnostic purposes and a shortened version (NOSIK) for screening purposes]. Lisse, The Netherlands: Swets \& Zeitlinger; 1992. Dutch.

35. Goodman R. The Strengths and Difficulties Questionnaire: a research note. J Child Psychol Psychiatry. 1997;38(5):581-586.

36. Van Widenfelt BM, Goedhart AW, Treffers PDA, Goodman R. Dutch version of the Strengths and Difficulties Questionnaire (SDQ). Eur Child Adolesc Psychiatry. 2003;12(6):281-289.
37. Achenbach TM. Manual for the Child Behavior Checklist and 1991 Profile. Burlington: University Associates in Psychiatry; 1991.

38. Verhulst FC, van der Ende J, Koot HM. Handleiding voor de CBCL/4-18. Rotterdam, The Netherlands: Erasmus University Rotterdam; 1996.

39. Snijders TAB, Bosker RJ. Multilevel Analysis: An Introduction to Basic and Advanced Multilevel Modeling. London: Sage; 1999.

40. Cohen J. Statistical Power Analysis for the Behavioral Sciences. 2nd ed. Hillsdale, NJ: Lawrence Earlbaum Associates; 1988.

41. Galland BC, Tripp E, Taylor BJ. The sleep of children with attention deficit hyperactivity disorder on and off methylphenidate: a matched case-control study. J Sleep Res. 2010;19(2):366-373.

42. Crowley SJ, Eastman CI. Phase advancing human circadian rhythms with morning bright light, afternoon melatonin, and gradually shifted sleep: can we reduce morning bright-light duration? Sleep Med. 2015 ; 16(2):288-297.

43. Saxvig IW, Wilhelmsen-Langeland A, Pallesen S, Vedaa O, Nordhus IH, Bjorvatn B. A randomized controlled trial with bright light and melatonin for delayed sleep phase disorder: effects on subjective and objective sleep. Chronobiol Int. 2014;31(1):72-86.
Nature and Science of Sleep

\section{Publish your work in this journal}

Nature and Science of Sleep is an international, peer-reviewed, open access journal covering all aspects of sleep science and sleep medicine, including the neurophysiology and functions of sleep, the genetics of sleep, sleep and society, biological rhythms, dreaming, sleep disorders and therapy, and strategies to optimize healthy sleep. The manuscript

\section{Dovepress}

management system is completely online and includes a very quick and fair peer-review system, which is all easy to use. Visit http://www. dovepress.com/testimonials.php to read real quotes from published authors. 